\title{
Extended negative impact of secondary infrastructure on the high conservation values of sparsely developed areas
}

\author{
Ricardo Morán-López, Juan M. Sánchez Guzmán \\ Alejandra Bettina Perales Casildo and Óscar Uceda Tolosa
}

\begin{abstract}
Although there is increasing evidence for the effects on wildlife of primary infrastructure (paved roads and human settlements), the effect of secondary infrastructure (tracks and isolated buildings) is generally assumed to be low in sparsely developed areas. We hypothesized that secondary infrastructure may have a negative effect similar to that of primary infrastructure, and hence may be the source of extended impacts in landscapes that are otherwise relatively undisturbed. We studied multi-year breeding site data for a community of large birds (raptors and storks) in the Monfragüe Biosphere Reserve, in the south-west Iberian Peninsula. Using a bootstrap model selection approach we modelled the distribution of breeding sites, using as predictors measures of habitat accessibility (relief, hydrography) and various types of infrastructure (primary and secondary) at different scales. Distance effect functions were developed. Secondary infrastructure exerted a negative effect on breeding sites that was equivalent to that of primary infrastructure, in terms of both transport (track vs road) and dwellings (scattered vs aggregated). The negative effect was distance (rather than density) mediated, and remained within the $1 \mathrm{~km}$ scale. The potential impact of secondary infrastructure is greater than that of primary infrastructure as it occupies more extensive areas and includes richer communities, with significant proportions of threatened populations. Our results contradict common assumptions about the negligible impact of secondary infrastructure on biodiversity, reveal new challenges for biodiversity conservation, and provide insights relevant for the spatial planning of isolated buildings and tracks in sparsely developed areas with species of conservation interest.
\end{abstract}

Keywords Breeding success, conservation, infrastructure impact, isolated buildings, threatened species, undisturbed landscapes, unpaved tracks

Ricardo Morán-López (Corresponding author), Juan M. Sánchez Guzmán, Alejandra Bettina Perales Casildo and Óscar Uceda Tolosa Grupo de Investigación en Biología de la Conservación, Área de Zoología, Universidad de Extremadura, Avda de Elvas s/n, 06071 Badajoz, Spain

E-mail rmoran@unex.es

Received 18 January 2016. Revision requested 3 March 2016. Accepted 15 March 2016. First published online 5 July 2016.

\section{Introduction}

T uman settlements and their concomitant transport in1 frastructure alter the landscape, leading to loss and fragmentation of wildlife habitats (Trombulak \& Frissell, 2000; Turner et al., 2004) and thus posing significant threats to local biodiversity (Benítez-López et al., 2010). Roads and other infrastructure, for example, result in direct mortality, altered behaviour, altered physical and chemical habitat, dissemination of alien species, increased anthropogenic disturbance and use of habitats, and fragmentation of populations (Trombulak \& Frissell, 2000; Brugiere et al., 2006; Benítez-López et al., 2010; Sinclair, 2010; González-Gallina et al., 2013). Urbanization also alters animal communities in a complex way related to the size, density and location of human populations (van der Zande et al., 1980; Clergeau et al., 2006; Vermaat et al., 2007; Pedrana et al., 2010; Randrianandrianina et al., 2010). Identifying which spatial pattern of human settlement has the least impact on biodiversity is important for the conservation of global biological diversity (Sutherland et al., 2009).

Birds are one of the most studied groups with respect to the sensitivity of wildlife to habitat disturbance caused by infrastructure, and there is significant variability within the group (Benítez-López et al., 2010). The effect of transport infrastructure on raptors, for example, is one of either indifference or attraction for small and medium-sized species (Meunier et al., 2000; Lambertucci et al., 2009) but of repulsion for larger species (Bautista et al., 2004; Lambertucci et al., 2009), which affects their breeding sites (Reijnen \& Foppen, 1994) and ultimately their reproductive success (e.g. Anthony \& Isaacs, 1989; Peach et al., 2008).

Reviews of the known effects of infrastructure (Trombulak \& Frissell, 2000; Fahrig \& Rytwinski, 2009; Benítez-López et al., 2010; Selva et al., 2011) indicate the conservation importance of maintaining existing sparsely developed areas. It is a misconception that most impacts are associated with major roads (Sun et al., 2009; van Langevelde et al., 2009). However, the impact of relatively minor infrastructure (e.g. minor roads and unpaved tracks) in areas of low development remains largely unknown (Kociolek et al., 2011). Unpaved tracks and isolated buildings (henceforth, secondary infrastructure) occupy significant areas even in developed countries (e.g. in Europe; EEA, 2006). 


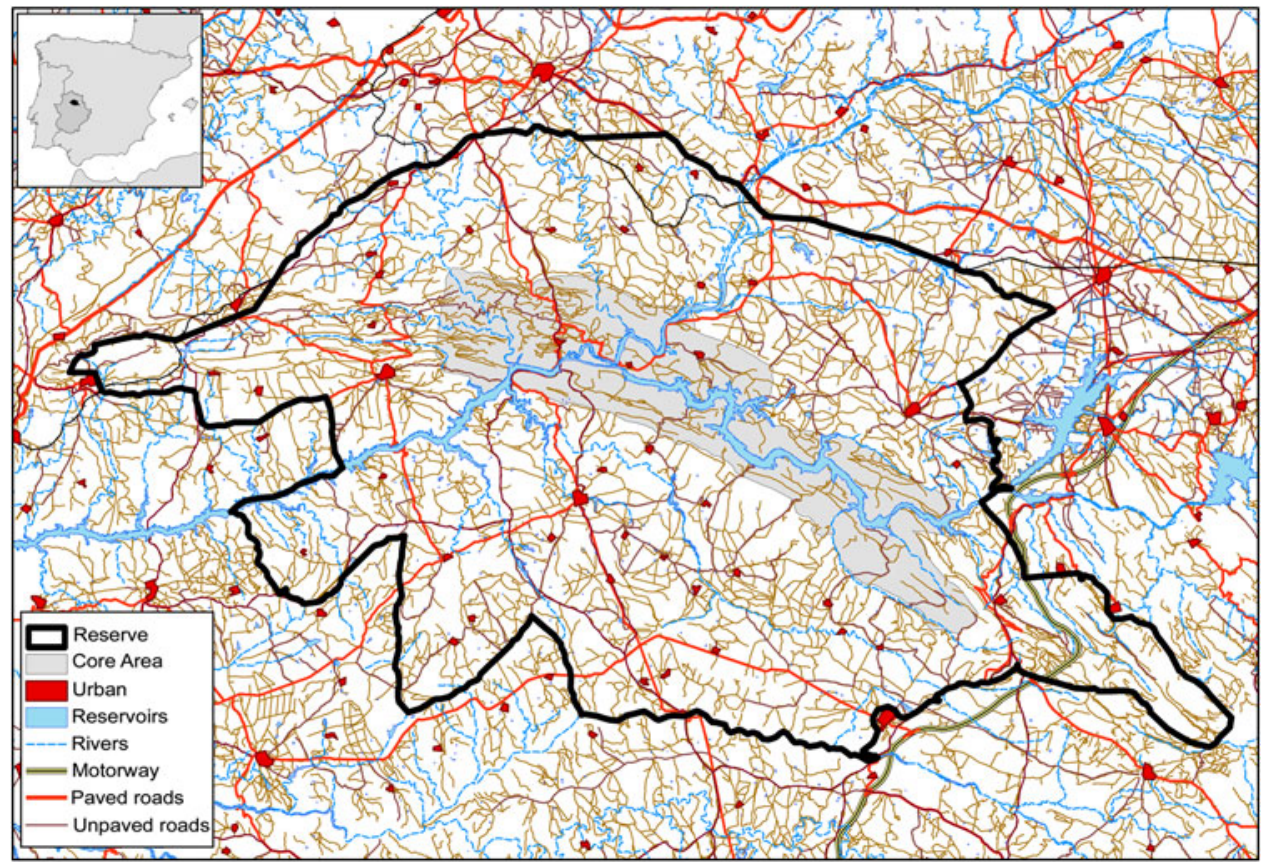

FIG. 1 The infrastructure elements, hydrological network, and delimitation of the core zone of the Monfragüe Biosphere Reserve in the south-western Iberian Peninsula.
We hypothesized that the breeding site selection and success (chicks flying from nests) of large birds is influenced by human settlements and transit infrastructure, particularly elements of secondary infrastructure in sparsely developed and relatively well-conserved landscapes. Given the known sensitivity of large birds to disturbance and the characteristic ranges of their response to such disturbance, the use they make of sparsely developed areas provides a good model with which to investigate the potential impacts of secondary infrastructure. We studied the spatial covariation of infrastructure and the breeding sites of large birds in a sparsely developed landscape, to address the following questions: Is there a repulsive influence of secondary infrastructure on the breeding site selection of large birds? Is it related to human dwellings, transit or both? In the first case, do isolated buildings exert an influence comparable to rural settlements? In the second case, do unpaved tracks exert an influence comparable to paved roads? Is the negative influence independent of, or associated with, features of the landscape?

\section{Study area and species}

We conducted the study in the Monfragüe Biosphere Reserve, a sparsely developed area with a typical agroforestry system that dominates the landscape of the southwestern Iberian Peninsula, called dehesa in Spain, where it covers c. 5.8 million ha (Joffre et al., 1999), and montado in Portugal, where it covers c. 1.2 million ha (Mendes, 2005). Traditional dehesa land use has been a sustainable system (Dawson \& Fry, 1998; García del Barrio et al., 2004), managed for centuries while maintaining high biodiversity and minimal transformation of the landscape (Díaz et al., 1997; Blondel \& Aronson, 1999; Plieninger \& Wilbrand, 2001). The Reserve is within the Mediterranean Biogeographical Region (Fig. 1). It consists of a 12,830 ha core zone, which is the Monfragüe National Park, with conservation and recreational use, a 15,360 ha buffer zone, and an 87,970 ha transition zone, which overlaps the Monfragüe and Surrounding Dehesas Special Protection Area (116,160 ha; European Birds Directive 2009/147/EC). There are 46 villages and hamlets within the Reserve, the seven largest of which have a total of 3,384 inhabitants (mean $=631.0 \pm \mathrm{SD}$ 585.8). The transport infrastructure consists of $2,659.1 \mathrm{~km}$ of unpaved tracks (89.3\%), $309.8 \mathrm{~km}$ of paved roads (10.4\%) and $7.8 \mathrm{~km}$ of motorway (0.3\%). The Reserve includes a combination of natural (forest and scrub) and moderately transformed (dehesa) areas, which support high biodiversity $(>1,300$ species of flora and $>200$ vertebrates; GIC, 2010), including a significant percentage of European populations of large bird species of conservation interest (e.g. the black stork Ciconia nigra, 0.4-0.5\%; Egyptian vulture Neophron percnopterus, 1.6-1.8\%; Iberian imperial eagle Aquila adalberti, 6.7\%; cinereous vulture Aegypius monachus, 22.2\%; BirdLife International, 2004).

We included in the analysis the locations of the nesting sites of large rock-dwelling and tree-dwelling birds, including the Accipitridae (diurnal raptors) and Ciconiidae (storks) families. Our criteria were to focus on the larger species of greatest conservation interest and with the best understood distributions. Long-term data from annual censuses of the Directorate General for the Environment 
TABLE 1 Variables used to characterize the UTM grid applied to the Monfragüe Biosphere Reserve in the south-west Iberian Peninsula (Fig. 1), with type, unit, and description.

\begin{tabular}{|c|c|c|}
\hline Variable & Type (unit) & Description \\
\hline dentrack1,3,5 & Density $\left(\mathrm{km}\right.$ per $\left.\mathrm{km}^{2}\right)$ & Density of (unpaved) tracks in the $1 \times 1,3 \times 3$ or $5 \times 5 \mathrm{~km} \mathrm{UTM} \mathrm{grids}$ \\
\hline denroad $1,3,5$ & Density $\left(\mathrm{km}\right.$ per $\left.\mathrm{km}^{2}\right)$ & Density of (paved) roads in the $1 \times 1,3 \times 3$ or $5 \times 5 \mathrm{~km} \mathrm{UTM} \mathrm{grids}$ \\
\hline denbuild1,3,5 & Density (no. per $\mathrm{km}^{2}$ ) & Density of buildings in the $1 \times 1,3 \times 3$ or $5 \times 5 \mathrm{~km}$ UTM grids \\
\hline densett $1,3,5$ & Density (no. per km²) & Human population density in the $1 \times 1,3 \times 3$ or $5 \times 5 \mathrm{~km}$ UTM grids \\
\hline denhydro1,3,5 & Density $\left(\mathrm{km}\right.$ per $\left.\mathrm{km}^{2}\right)$ & Density of rivers in the $1 \times 1,3 \times 3$ or $5 \times 5 \mathrm{~km}$ UTM grids \\
\hline disttrack & Distance $(\mathrm{m})$ & Mean distance to tracks in the $1 \mathrm{~km}$ UTM grid \\
\hline distroad & Distance $(\mathrm{m})$ & Mean distance to roads in the $1 \mathrm{~km}$ UTM grid \\
\hline distbuild & Distance $(\mathrm{m})$ & Mean distance to buildings in the $1 \mathrm{~km}$ UTM grid \\
\hline disthydro & Distance $(\mathrm{m})$ & Mean distance to rivers in the $1 \mathrm{~km}$ UTM grid \\
\hline distsettlem & Distance $(\mathrm{m})$ & Mean distance to towns or villages in the $1 \mathrm{~km}$ UTM grid \\
\hline demrange $1,3,5$ & Relief (m) & Altitude range in the $1 \times 1,3 \times 3$ or $5 \times 5 \mathrm{~km}$ UTM grids \\
\hline demsd1,3,5 & Relief (m) & Standard deviation of the altitude in the $1 \times 1,3 \times 3$ or $5 \times 5 \mathrm{~km} \mathrm{UTM}$ grids \\
\hline slope $1,3,5$ & Relief $\left(^{\circ}\right)$ & Mean slope in the $1 \times 1,3 \times 3$ or $5 \times 5 \mathrm{~km}$ UTM grids \\
\hline flatprop & Relief (\%) & Fraction of flat area in the $1 \mathrm{~km}$ UTM grid \\
\hline valprop & Relief (\%) & Fraction of valley area in the $1 \mathrm{~km}$ UTM grid \\
\hline hillsprop & Relief (\%) & Fraction of hill area in the $1 \mathrm{~km}$ UTM grid \\
\hline
\end{tabular}

(DGMN, Junta de Extremadura) and studies of the Conservation Biology Research Group (GIC, University of Extremadura) are available in databases for the period 1986-2002. These data are the product of coordinated, synchronized censuses covering the entire study area, carried out during the breeding season by rangers and researchers of these institutions (e.g. Morán-López et al., 2006a,b). More recent data that fulfilled our criteria were unavailable. The 1986-2002 data are the best available, up-to-date, longterm data for a sparsely developed Mediterranean landscape of conservation relevance, and we verified their attributes and spatial quality. Reports (e.g. GIC, 2010) indicate that the environmental and socio-economic situation in the Reserve has remained essentially constant to the present.

\section{Methods}

To facilitate a reliable comparison of census data and consideration of all the nesting areas we established a spatiotemporal scale defined by a $1 \mathrm{~km}$ grid (UTM grid) and multi-year censuses (1986-2002). This temporal grain size is greater than that of any of the available surveys (e.g. Northrup et al., 2012) and facilitates a more reliable description of large-bird breeding conditions (Gutzwiller \& Barrow, 2003). Infrastructure effects are probably synergistic, complex, cumulative and time-lagged (EEA, 2011; Selva et al., 2011), and thus relationships derived from a single census and year would not describe them adequately. With respect to the spatial grain size, numerous studies have found scales of one to several kilometres to be adequate to study bird distribution, habitat use and the effects of infrastructure (e.g. Gutzwiller \& Barrow, 2003; Morán-López et al., 2006a; Benítez-López et al., 2010; Schwenk \& Donovan, 2011, and references therein). The $1 \mathrm{~km}$ filtering rule has been found to be useful for eliminating spatial autocorrelation resulting from clumped observations (Telford \& Birks, 2009). Accordingly, we used this same spatial scale to characterize both species distribution and predictors.

We followed a multispecies study framework, as such an approach has been found to be useful in quantitative assessments for conservation planning (Bonn \& Schröder, 2001; Dallimer et al., 2009; Schwenk \& Donovan, 2011). Multispecies models (1) constitute a more parsimonious, general approach, which follows the precautionary principle in identifying key human influences; (2) overcome difficult and subjective trade-offs among species; and (3) facilitate understanding of collective responses of communities to human influences. For all the grid squares in the study area we determined the presence or absence of nesting sites of any of the study species in any year.

The analysis of dichotomous variables may be negatively affected by highly imbalanced prevalences of the species in the data (i.e. the presence/absence ratio having many more absences than presences; Franklin et al., 2009). Our sampling strategy was to take random samples of absence data of the same size as the presence datasets. To avoid results being contingent on just one subsample, we followed a bootstrap resampling approach while maintaining prevalence and sample size for robust parameter and confidence interval estimation (Burnham \& Anderson, 2002).

\section{Landscape and infrastructure data}

The grid squares were characterized by digital cartography in a geographical information system used to measure the explanatory variables. We selected potential mediating factors of human disturbance (e.g. noise, light) and accessibility (cost of transiting the terrain) in the environment of nests. In each grid square we measured 16 variables (Table 1) 
characterizing the spatial distribution of the transit infrastructure (paved or unpaved) and human dwellings (population in clustered settlements or isolated buildings), and natural elements of the landscape that impeded accessibility (relief and hydrography), increasing the cost of transiting the terrain. We evaluated the functioning of alternative spatial measurements (as we had no prior knowledge of which type of measure would be a better indicator of spatially mediated effects), using densities, distances and percentage occupancy of the grid squares. The measurements were made in the $1 \times 1 \mathrm{~km}$ UTM grid and in $3 \times 3$ and $5 \times 5$ grids (Table 1). We were thus able to evaluate uncertainty related to the spatial range of influence of the potential factors mediating accessibility. However, some variables (the form of the terrain and the minimum distances) were measured only in the $1 \times 1 \mathrm{~km}$ grid. This was under the assumption that their potential influence would be exerted in the vicinity of the nests and not over an extended spatial environment (e.g. Morán-López et al., 2006a,b).

\section{Data analysis}

We analysed all data using SPSS 15.0 (IBM, Armonk, USA). We performed a non-parametric Spearman correlation analysis (Zar, 1996) between all the predictors, to exclude those that were highly correlated $\left(r_{s}>0.9, \mathrm{P}<0.05\right)$ and to facilitate interpretation. We also inspected bivariate scatterplots relating the dependent variable to its predictors, to establish the expected form (linear, monotonic, etc.) of the responses and decide on the most suitable transformations to include in the models. The variables were subsequently standardized to avoid bias resulting from differences in the measurement units.

We investigated the hypothesized impacts by constructing a set of generalized linear models using a binomial distribution and a logistic link function appropriate for dichotomous data. To evaluate the individual and collective explanatory capacity of each type of factor (distance, density or relief) and scale of influence $(1,3$ or $5 \mathrm{~km})$ on nest site presence we constructed models for each type of descriptor and scale (individual models), then all types by scale (conjoint models), and finally all types and scales (full model). The total set comprised 11 models and 25 parameters. We used a model selection approach based on the bias-adjusted Akaike's information criterion $\left(\mathrm{AIC}_{c}\right.$; Burnham \& Anderson, 2002) to provide evidence for the hypothesized impacts (and their scale), to quantify the independent influence of infrastructure vs relief variables, to compare the contribution of secondary vs primary infrastructure, and to identify combinations of variables that would be useful to guide species conservation (see, for example, inferential strength and competing hypotheses in Stephens et al., 2005; Roedenbeck et al., 2007).

Calculating parameter estimates and confidence intervals conditional on only one random sample would not explore the uncertainty in the identification of factors that could have utility and general application to species conservation. We therefore used bootstrap resampling of the data, maintaining sample size and prevalence $(B=999$ samples of size $R=312$ ), followed by model selection. We used model selection relative frequencies $\left(p_{i}\right)$ to select the best model, and took as included in the best model the estimated parameters whose bootstrapped confidence limits excluded the value zero (Burnham \& Anderson, 2002).

We found that the location of the infrastructure was not independent of the characteristics of the relief (Spearman analysis), which could result in inferences that confuse the independent effects of the former (e.g. disturbances) with other effects associated with the latter (e.g. land use or habitat) (Fahrig \& Rytwinski, 2009). We therefore removed the possibility of the influence of habitat in the models by including the infrastructure variables after removing the effect of relief, a proxy for habitat, to which end we replaced the predictors by the residual of a regression of the (dependent) infrastructure variables against the (independent) relief (Legendre, 1993). This has the effect of removing the influence of land use on infrastructure variables through relief (Fahrig \& Rytwinski, 2009).

Socio-economic, environmental and biological data may reflect spatial patterns that depend on the factors generating them (Anselin, 1988; Carroll \& Pearson, 200o). It is advisable to measure any potential spatial autocorrelation in the data or the residuals, as its presence may be an indicator of absent factors or contagious processes, as well as of pseudo-replication, and to include or exclude it from the models if it is present. We created Moran's I correlograms (Legendre \& Legendre, 1998) with the standardized residuals of the models (lag $1 \mathrm{~km}$, extent $50 \mathrm{~km}$ ) to determine the existence of spatial autocorrelation in the error. A Bonferroni correction was applied because the technique involves multiple tests.

Confidence in the performance of the models generated and their utility for species conservation is founded in proper model validation. For this purpose we followed a three-way approach, combining the attributes of same/new data, same/ new type of data and same/new location of data. Firstly, we calculated receiver operating characteristic plots for 999 random bootstrap samples of size 40 (Buckland \& Elston, 1993) in the Monfragüe Biosphere Reserve, and measured accuracy as a mean and standard deviation of the area under the curve (same data, same type, same place). Secondly, we calculated the receiver operating characteristic plot and the area under the curve value in the Sierra de San Pedro Special Protection Area, located c. $90 \mathrm{~km}$ from the Reserve (new data, same type, different place). Thirdly, we correlated the summed breeding success by $1 \mathrm{~km}^{2}$ of the most abundant raptor, the cinereous vulture (data from 2000; Morán-López et al., $2006 \mathrm{~b}$ ), with the linear predictor of the model (new data, different type, same place), using the Spearman coefficient. 
TABLE 2 Number of $1 \mathrm{~km}$ grid squares in the Monfragüe Biosphere Reserve (Fig. 1) where large-bird species were present; \% of the total number of squares occupied by any of the species $(n=156)$; and $\%$ of the total number of squares in the Reserve, with or without species presence $(n=1,336)$.

\begin{tabular}{|c|c|c|c|}
\hline \multirow[b]{2}{*}{ Species } & \multicolumn{3}{|c|}{$1 \mathrm{~km}$ grid squares in the Monfragüe Biosphere Reserve } \\
\hline & Number & $\begin{array}{l}\% \text { of total squares } \\
\text { with species presence }\end{array}$ & $\begin{array}{l}\% \text { of all squares } \\
\text { in the Reserve }\end{array}$ \\
\hline Aegypius monachus & 88 & 56.4 & 6.6 \\
\hline Neophron percnopterus & 37 & 23.7 & 2.8 \\
\hline Gyps fulvus & 32 & 20.5 & 2.4 \\
\hline Aquila adalberti & 10 & 6.4 & 0.7 \\
\hline Aquila chrysaetos & 7 & 4.5 & 0.5 \\
\hline Hieraaetus fasciatus & 11 & 7.1 & 0.8 \\
\hline Ciconia nigra & 22 & 14.1 & 1.6 \\
\hline Total (presence/absence) & $156 / 1180$ & & $11.7 / 88.3$ \\
\hline
\end{tabular}

${ }^{*}$ The percentages are non-additive, as squares may be used by more than one species.

Finally, we developed distance effect functions to apply the new knowledge generated by the study to animal conservation practice. To this end, we created empirical probability of occupancy models relating the large-bird community to the secondary infrastructure of unpaved tracks and isolated buildings. Individual models by variable (including its quadratic term) were generated using the bootstrap generalized linear modelling approach described above $(B=999$, $R=312$ ) with the original data (i.e. no transformation or standardization). A bivariate track vs building model was also created to further explore interaction effects in addition to the aforementioned nonlinear relations.

\section{Results}

\section{Species and nesting sites}

Seven species, including threatened species, met the criteria of body size and availability of monitoring data of sufficient quality. These selected species nest in $156(11.7 \%)$ of the 1,336 $1-\mathrm{km}$ UTM squares of the Monfragüe Biosphere Reserve, thus leaving 1,180 (88.3\%) unoccupied squares (Table 2). Presence squares were denser in the core zone and the cinereous vulture was the most frequent species, but the contribution of the group of remaining species was comparable and the resulting locations were distributed across all three zones of the Reserve. This provides support for the limits of the Reserve and the multi-species and multi-year data being adequate to describe breeding environments according to the study objectives.

\section{Influence of infrastructure on breeding sites}

Infrastructure and relief at the $1 \mathrm{~km}$ scale (conjoint $1 \mathrm{~km}$ model) received strong support in the bootstrap model selection procedure, whereas the remaining models received
TABLE 3 Results of the bootstrap model selection procedure, with mean values and standard deviations of $\mathrm{AIC}_{\mathfrak{c}}$, and selection frequencies.

\begin{tabular}{lll}
\hline Model $^{*}$ & $\begin{array}{l}\text { Bootstrap AICc } \\
(\text { mean } \pm \text { SD })\end{array}$ & $\begin{array}{l}\text { Model selection } \\
\text { relative frequency }(\pi \mathrm{i})\end{array}$ \\
\hline conjoint1 & $341.65 \pm 14.27$ & 0.96 \\
Full & $350.02 \pm 14.53$ & 0.04 \\
relief1 & $357.18 \pm 16.10$ & 0.00 \\
conjoint3 & $368.44 \pm 14.18$ & 0.00 \\
relief3 & $381.69 \pm 15.54$ & 0.00 \\
conjoint5 & $388.58 \pm 14.24$ & 0.00 \\
relief5 & $407.63 \pm 15.39$ & 0.00 \\
density5 & $532.72 \pm 12.92$ & 0.00 \\
Distance & $537.94 \pm 14.02$ & 0.00 \\
density3 & $541.67 \pm 13.18$ & 0.00 \\
density1 & $562.37 \pm 13.55$ & 0.00 \\
\hline
\end{tabular}

${ }^{\star}$ Each model is based on different predictors (distance, density or relief) and scales $(1,3$ or $5 \mathrm{~km}$ ), combined by scale (conjoint models) or including all types and scales (full model).

weak or no support (Table 3). No predictors other than distance to infrastructure and the relief characteristics within $1 \mathrm{~km}$ received substantial support at any scale. Both primary and secondary infrastructure, including transport and settlement, were included in the best model (conjoint 1 $\mathrm{km}$ model; Table 4). The influence of secondary infrastructure was comparable to that of primary infrastructure, both in transport (tracks vs roads) and settlement (isolated buildings vs villages), and relief showed a strong effect (Table 4).

The validation results indicated that the conjoint $1 \mathrm{~km}$ model performed well both inside and outside the study area. The receiver operating characteristic plots showed high accuracy inside the Reserve (area under the curve $=0.9$ ), with the model also being useful for application in the Special Protection Area (area under the curve = 0.7; Table 5; Fig. 2). Probability thresholds equilibrating sensitivity (true positive fraction) and specificity (true negative fraction) showed 
TABLE 4 Results of the conjoint $1 \mathrm{~km}$ model bootstrap resampling estimation of parameters.

\begin{tabular}{lrl}
\hline Parameter $^{*}$ & \multicolumn{1}{c}{$B$} & SD \\
\hline disttrack & 0.32 & 0.14 \\
distroad & 0.48 & 0.16 \\
distbuild & 0.39 & 0.11 \\
distsettlem & 0.31 & 0.12 \\
slope1 & 8.61 & 0.65 \\
hillsprop & -10.12 & 2.84 \\
\hline
\end{tabular}

${ }^{*}$ Only the predictors whose $99 \%$ bootstrapped confidence limits excluded zero are shown.

TABLE 5 Results of the conjoint $1 \mathrm{~km}$ model validation process inside (Monfragüe Biosphere Reserve) and outside (Sierra de San Pedro Special Protection Area) the calibrating area; the results for the Reserve are from a bootstrap validation approach. Threshold-dependent results are shown at cut-off values that equilibrate positive and negative misclassifications.

\begin{tabular}{lll}
\hline & $\begin{array}{l}\text { Monfragüe } \\
\text { Biosphere Reserve }\end{array}$ & $\begin{array}{l}\text { Sierra de San } \\
\text { Pedro Special } \\
\text { Protection Area }\end{array}$ \\
\hline AUC $_{C}$ & $0.90 \pm$ SD 0.05 & 0.73 \\
Sensitivity & $0.82 \pm$ SD 0.08 & 0.73 \\
Specificity & $0.83 \pm$ SD 0.08 & 0.73 \\
False positive & $0.18 \pm$ SD 0.08 & 0.27 \\
False negative & $0.17 \pm$ SD 0.08 & 0.27 \\
\hline
\end{tabular}

correct classification of $>80 \%$ and $>70 \%$ (including breeding and non-breeding areas) inside (Reserve) and outside (Special Protection Area) the study area, respectively. Breeding success of the cinereous vulture in the Reserve was positively correlated with the linear predictor of the model $\left(r_{s}=0.28, \mathrm{P}=0.04, \mathrm{n}=52\right)$.

We found the covariance of relief and infrastructure to be associated with the slope in all the infrastructure variables, with increasing distance and decreasing density of infrastructure elements corresponding to greater slopes (corrector model results not shown), confirming the adequacy of our approach in removing the effect of relief on infrastructure variables. No model showed spatial autocorrelation in the residuals (Moran's I, P > 0.05 in all cases). We could therefore exclude the existence of spatial autocorrelation.

Empirical models relating probability of occupancy to secondary infrastructure showed significant linear relationships in every descriptor $(\mathrm{P}<0.05)$, but no quadratic ones $(\mathrm{P}>0.10)$. Distance to tracks, isolated buildings, and their interaction were significant in these models (Figs $3 \& 4$ ). The probability of large birds breeding in the Reserve was higher the more distant the site from tracks and buildings, with tracks showing a more intense shorter distance effect than buildings. A probability-of-occurrence range of $0.95-$ 0.99 is reached at distances of $0.5-0.7 \mathrm{~km}$ from tracks and $3.4-4.5 \mathrm{~km}$ from buildings. The areas of the Reserve

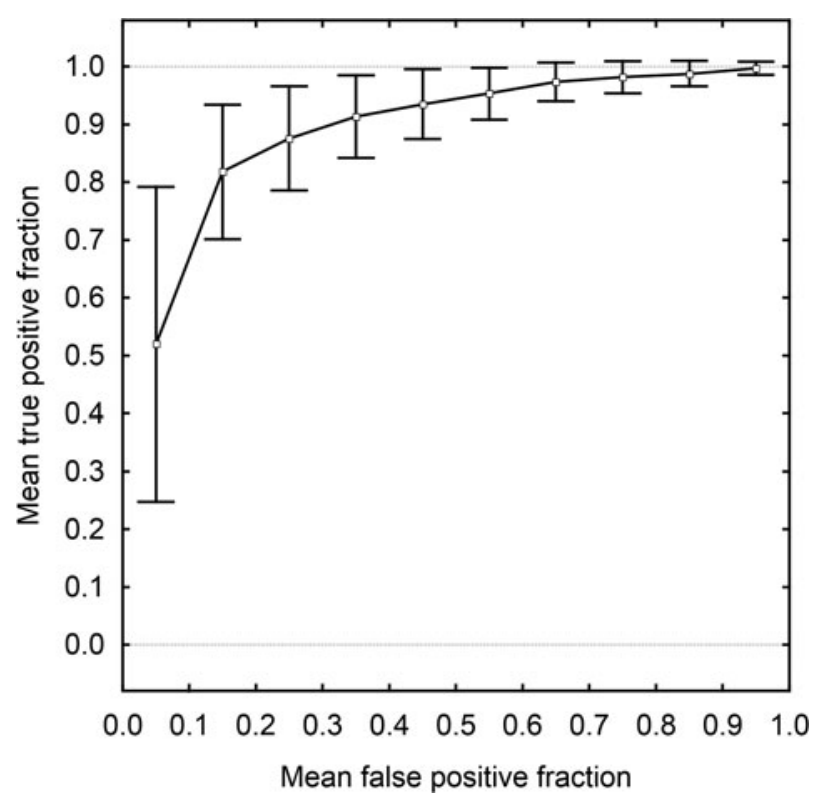

FIG. 2 Receiver operating characteristic plot with mean and standard deviation of the true positive fraction, for the conjoint 1 $\mathrm{km}$ model (see text for details) validated in the Monfragüe Biosphere Reserve (Fig. 1) using bootstrap resampling; $\mathrm{AUC}=0.899 \pm \mathrm{SD} 0.051$.

contained within these probabilities are $95.2-99.0 \%$ for tracks and $100 \%$ for isolated buildings.

\section{Discussion}

Previous studies have shown that both the presence of the principal transport infrastructure (paved roads) and the intensity of traffic alter the behaviour of large birds in their foraging and breeding areas (Meunier et al., 2000; Trombulak \& Frissell, 2000; Bautista et al., 2004; Kociolek et al., 2011). We have demonstrated the significant effect of secondary infrastructure even in an area of sparse development, where unpaved tracks and isolated buildings have displaced the breeding sites of large birds. Furthermore, although the intensity of the effect was comparable to that of primary infrastructure, the spatial extension of the effect of secondary infrastructure was far greater (by a factor of c. 9), resulting in a larger size effect.

This comparable negative effect of secondary infrastructure relative to that of primary infrastructure is particularly informative, as it has commonly been assumed that low levels of development in rural areas have relatively little or no impact on wildlife populations. This assumption has resulted in the potential effect of secondary infrastructure receiving only minor attention in the scientific literature and management practice (e.g. Kociolek et al., 2011). However, mitigation of these negative effects is important in protected areas and in general in relatively undisturbed areas where unpaved tracks constitute a major fraction of 


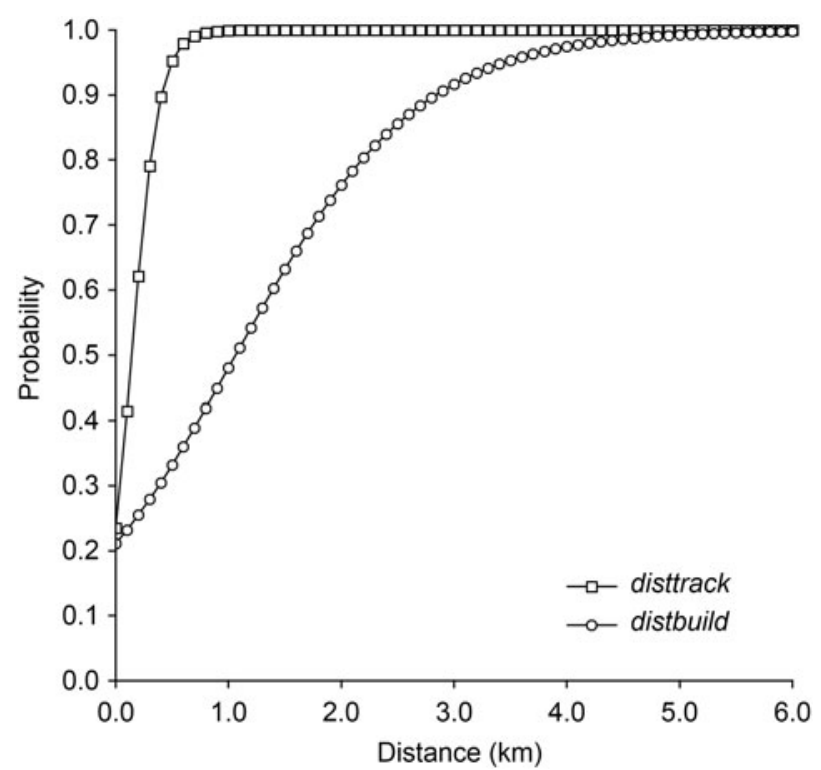

FIG. 3 Predicted probability of occurrence of breeding of large birds in relation to distance from unpaved tracks (disttrack) or isolated buildings (distbuild). Linear predictors of the logistic models are (coefficients $\mathrm{P}<0.05$ included; quadratic coefficients $\mathrm{P}>0.10$ excluded $): \mathrm{P}($ disttack $)=-1.18+8.37$ disttrack; $\mathrm{P}($ distbuild $)=-1.32+1.24$ distbuild.

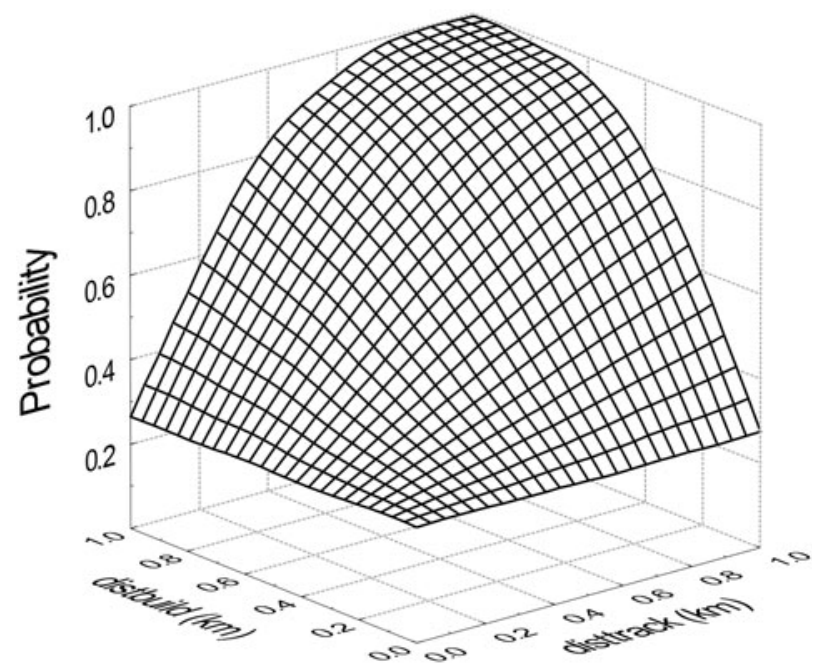

FIG. 4 Predicted probability of occurrence of breeding of large birds in relation to the interaction between distance from unpaved tracks (disttrack) and isolated buildings (distbuild). The linear predictor of the logistic model is (coefficients $\mathrm{P}<0.0001$ ): $-0.96+6.37$ disttrack $\times$ distbuild.

a transit infrastructure that extends over large areas, which are supposed to buffer wildlife populations from human activities. In Spain's Extremadura region, for example, which is an important region for biodiversity conservation, unpaved tracks represent $84.3 \%$ of the transport infrastructure, $86.0 \%$ of the Natura 2000 Network transport infrastructure, and $89.3 \%$ of the Monfragüe Biosphere Reserve transport infrastructure. Considering that the principal strategy used to mitigate the negative effects of infrastructure is to minimize infrastructure development in relatively undisturbed areas (Trombulak \& Frissell, 200o; Benítez-López et al., 2010), neglecting secondary infrastructure in wildlife conservation management is a shortcoming.

The breeding habitats of the large birds of the Monfragüe Biosphere Reserve are characterized by gentle slopes, whereas areas of more rugged relief are avoided. Variable relief offers greater protection from predators, and acts as a buffer against human disturbance. Breeding in rugged areas would be limited by factors such as the reduced availability of suitable habitats, and adverse weather conditions (Newton, 1979). The predominant explanatory power of relief in the best model marks it as an indicator of suitable breeding habitats for large birds, as well as being a limiter for accessibility.

The results suggest that the construction of unpaved tracks and isolated buildings has a negative impact on large bird species, regardless of the forms of the relief. This points to their breeding sites being sensitive to such infrastructure not only in the more rugged core zone but also in the buffer and transition zones. This knowledge provides a common framework for spatial and year-long planning throughout the zones of the Reserve, not just in the core zone, which is preferentially targeted for conservation and recreational uses. We therefore recommend that the principal strategy to minimize infrastructure in relatively undisturbed areas should be extended to also include secondary infrastructure (Trombulak \& Frissell, 2000; Benítez-López et al., 2010; Selva et al., 2011). Avoidance of infrastructure by birds, both colonial and territorial, may be the cause of anything from spatial displacement to an over-saturation of breeding habitats, resulting in net population losses because of the effect on reproductive success and productivity (van der Zande et al., 1980).

The increased accessibility and use of areas in proximity to nests as a result of the construction of secondary infrastructure (tracks and isolated buildings) has had a generalized negative effect on habitat selection by large birds, and on their breeding success. The levelling off of large-bird populations in the Reserve (GIC, 2010) is indicative of a state of over-saturation that may reduce the chances of recovery of threatened species, a state conditioned, at least in part, by the development of secondary infrastructure. We found a negative effect of infrastructure on the breeding success of the largest raptor (A. monachus) in the core zone of the Reserve, where most of the infrastructure is secondary.

Once this general negative response has been confirmed, an analysis by species, and a specific consideration of nonlinear relationships and breeding success, will help to reveal the mechanisms and costs involved (e.g. D'Amico et al., 2016). For species-specific models to be useful in species conservation, the differences in model outcomes must be 
interpreted properly with respect to the biology and ecology of each species (e.g. Mihoub et al., 2014), and the species' mechanistic responses to single or interacting human factors must be disentangled appropriately. The specific uses of every track and isolated building should also be considered, differentiating transport from access, and agricultural from recreational uses, and where and when they take place. However, this is not an easily affordable task in terms of resources and time. The community-level, multi-year infrastructure response models developed in this study provide a method with which to bridge the gap between conservation objectives and management practice.

\section{Conclusions}

Unpaved tracks and isolated buildings are the main centres of human activity in protected spaces, private estates and sparsely populated rural areas with semi-natural or natural land uses. This is why the effect of distance on the breeding sites of large birds indicates a widespread impact of human activity, wider than that of primary infrastructure in these areas. It will be a challenge to discern and separate the causal bases for each of the affected species. Nonetheless, the common pattern revealed by this community of breeding large birds provides evidence of the need for conservation management, primarily the development of a strategic plan that includes a spatial design for the construction and maintenance of secondary infrastructure, and its relocation or elimination where appropriate. Distance effect functions showed an influence of tracks only in close proximity $(\leq 700 \mathrm{~m}$ ) to breeding sites, spatially restricting the necessity for such management. The politically and socially admissible limits can be set based on empirical data and distance effect functions such as those reported here.

Based on current evidence it would be advisable to assess the contribution of the existing network of buildings and tracks, (not only in protected areas but also in sparsely developed regions, beyond them) to determine the appropriate actions to take. Such information would facilitate quantitative, evidence-based decision making regarding the extent of secondary infrastructure removal/displacement that is needed to achieve a given increase in the probability of a threatened species breeding, or to avoid the abandonment of the use of the area for breeding.

\section{Acknowledgements}

The data used in the study were provided by the General Directorate of the Environment of the Junta de Extremadura and the Group of Investigation in Conservation Biology of the University of Extremadura. We thank in particular the environment agents responsible for obtaining a better understanding of the distribution of bird populations in the Monfragüe Biosphere Reserve and the Sierra de San Pedro Special Protection Area, and the estate owners who allowed access to their properties. The study was funded through the agreement between the University of Extremadura and the Ministry of the Environment and Rural and Marine Affairs entitled 'Trabajos de seguimiento del estado ambiental de las Reservas de la Biosfera de la Comunidad Autónoma de Extremadura [Works monitoring the environmental status of the Biosphere Reserves of the Autonomous Community of Extremadura]'. The Consejería de Economía, Comercio e Innovación (Junta de Extremadura) funded the translation of the manuscript (GR10174).

\section{References}

Anselin, L. (1988) Spatial Econometrics: Methods and Models. Kluwer, Dordrecht, The Netherlands.

Anthony, R.G. \& IsaAcs, F.B. (1989) Characteristics of bald eagle nest sites in Oregon. The Journal of Wildlife Management, 53, 148-159.

Bautista, L.M., García, J.T., Calmaestra, R.G., Palacín, C., Martín, C.A., Morales, M.B. et al. (2004) Effect of weekend road traffic on the use of space by raptors. Conservation Biology, 18, $726-732$.

Benítez-López, A., Alkemade, R. \& Verweij, P.A. (2010) The impacts of roads and other infrastructure on mammal and bird populations: a meta-analysis. Biological Conservation, 143, 1307-1316.

Birdife International (2004) Birds in the European Union: A Status Assessment. BirdLife International, Wageningen, The Netherlands.

Blondel, J. \& Aronson, J. (1999) Biology and Wildlife of the Mediterranean Region. Oxford University Press, Oxford, UK.

BonN, A. \& SCHRÖDER, B. (2001) Habitat models and their transfer for single and multi species groups: a case study of carabids in an alluvial forest. Ecography, 24, 483-496.

Brugiere, D., Badjinca, I., Silca, C., Serra, A. \& Barry, M. (2006) On the road to extinction? The status of elephant Loxodonta africana in Guinea Bissau and western Guinea, West Africa. Oryx, 4O, 442-446.

Buckland, S.T. \& Elston, D.A. (1993) Empirical models for the spatial distribution of wildlife. Journal of Applied Ecology, 30, 478-495.

Burnham, K.P. \& Anderson, D.R. (2002) Model Selection and Multimodel Inference: A Practical-Theoretic Approach. 2nd edition. Springer-Verlag, Berlin, Germany.

Carroll, S.S. \& Pearson, D.L. (200o) Detecting and modeling spatial and temporal dependence in conservation biology. Conservation Biology, 14, 1893-1897.

Clergeau, P., Croci, S., Jokimäki, J., Kaisanlahti-Jokimäki, M. L. \& Dinetti, M. (2006) Avifauna homogenisation by urbanisation: analysis at different European latitudes. Biological Conservation, 127, 336-344.

Dallimer, M., King, T. \& Atkinson, R.J. (2009) Pervasive threats within a protected area: conserving the endemic birds of São Tomé, West Africa. Animal Conservation, 12, 209-219.

D’Amico, M., Périquet, S., Román, J. \& Revilla, E. (2016) Road avoidance responses determine the impact of heterogeneous road networks at a regional scale. Journal of Applied Ecology, 53, 181-19o. 
Dawson, T. \& Fry, R. (1998) Agriculture in nature's image. Trends in Ecology and Evolution, 13, 50-51.

Díaz, M., Campos, P. \& Pulido, F.J. (1997) The Spanish dehesas: a diversity in land-use and wildlife. In Farming and Birds in Europe. The Common Agricultural Policy and its Implications for Bird Conservation (eds D.J. Pain \& M.W. Pienkowski), pp. 178-209. Academic Press, London, UK.

EeA (European Environment Agency) (2006) Urban sprawl in Europe-The Ignored Challenge. EEA Report $\mathrm{n}^{\circ}$ 10/2006. European Environment Agency, Copenhagen, Denmark.

EeA (European Environment Agency) (2011) Landscape Fragmentation in Europe. EEA Report $\mathrm{n}^{\circ}$ 2/2011. European Environment Agency, Copenhagen, Denmark.

Fahrig, L. \& Rytwinski, T. (2009) Effects of roads on animal abundance: an empirical review and synthesis. Ecology and Society, $14,21$.

Franklin, J., Wejnert, K.E., Hathaway, S.A., Rochester, C.J. \& FISHER, R.N. (2009) Effect of species rarity on the accuracy of species distribution models for reptiles and amphibians in southern California. Diversity and Distributions, 15, $167-177$.

García Del Barrio, J.M., Bolaños, F., Ortega, M. \& ElenaRosello, R. (2004) Dynamics of land use and land cover change in Dehesa landscapes of the "REDPARES" network between 1956 and 1998. Advances in Geoecology, 37, 47-54.

GiC (Grupo de Investigación en Biología de la Conservación) (2010) Reserva de la Biosfera de Monfragüe. Informe anual 2009. Universidad de Extremadura, Badajoz, Spain.

González-Gallina, A., Benítez-Badillo, G., Rojas-Soto, O.R. \& Hidalgo-Minart, M.G. (2013) The small, the forgotten and the dead: highway impact on vertebrates and its implications for mitigation strategies. Biodiversity and Conservation, 22, 325-342.

GUtZWiller, K.J. \& BARROW, JR, W.C. (2003) Influences of roads and development on bird communities in protected Chihuahuan Desert landscapes. Biological Conservation, 113, 225-237.

Joffre, R., Rambal, S. \& Ratte, J.P. (1999) The dehesa system of southern Spain and Portugal as a natural ecosystem mimic. Agroforestry Systems, 45, 57-79.

Kociolek, A.V., Clevenger, A.P., St Clair, C.C. \& Proppe, D.S. (2011) Effects of road networks on bird populations. Conservation Biology, 25, 241-249.

Lambertucci, S.A., Speziale, K.L., Rogers, T.E. \& Morales, J.M. (2009) How do roads affect the habitat use of an assemblage of scavenging raptors? Biodiversity and Conservation, 18, 2063-2074.

LEGENDRE, P. (1993) Spatial autocorrelation: trouble or new paradigm? Ecology, 74, 1659-1673.

Legendre, P. \& Legendre, L. (1998) Numerical Ecology. 2nd edition. Elsevier Science, B.V., Amsterdam, The Netherlands.

Mendes, A.M.S.C. (2005) Portugal. In Valuing Mediterranean Forests: Towards Total Economic Value (eds M. Merlo \& L. Croitoru), pp. 331-352. CAB International, Wallingford, UK.

Meunier, F.D., Verheyden, C. \& Jouventin, P. (2000) Use of roadsides by diurnal raptors in agricultural landscapes. Biological Conservation, 92, 291-298.

Minoub, J.-B., Jiguet, F., Lécuyer, P., Eliotout, B. \& Sarrazin, F. (2014) Modelling nesting site suitability in a population of reintroduced Eurasian black vultures Aegypius monachus in the Grands Causses, France. Oryx, 48, 116-124.

Morán-López, R., Sánchez Guzmán, J.M., Borrego, E.C. \& SÁNCHEZ, A.V. (2006a) Nest-site selection of endangered cinereous vulture (Aegypius monachus) populations affected by anthropogenic disturbance: present and future conservation implications. Animal Conservation, 9, 29-37.

Morán-López, R., Sánchez, J.M., Costillo, E., Corbacho, C. \& Villegas, A. (2006b) Spatial variation in anthropic and natural factors regulating the breeding success of the cinereous vulture (Aegypius monachus) in the SW Iberian Peninsula. Biological Conservation, 130, 169-182.

Newton, I. (1979) Population Ecology of Raptors. T. \& A.D. Poyser Ltd, Berkhamsted, UK.

Northrup, J.M., Stenhouse, G.B. \& Boyce, M.S. (2012) Agricultural lands as ecological traps for grizzly bears. Animal Conservation, 15, 369-377.

Peach, W.J., Vincent, K.E., Fowler, J.A. \& Grice, P.V. (2008) Reproductive success of house sparrows along an urban gradient. Animal Conservation, 11, 493-503.

Pedrana, J., Bustamante, J., Travaini, A. \& Rodríguez, A. (2010) Factors influencing guanaco distribution in southern Argentine Patagonia and implications for its sustainable use. Biodiversity and Conservation, 19, 3499-3512.

Plieninger, T. \& Wilbrand, C. (2001) Land use, biodiversity conservation and rural development in the dehesas of Cuatro Lugares, Spain. Agroforestry Systems, 51, 23-34.

Randrianandrianina, F.H., Racey, P.A. \& Jenins, R.K.B. (2010) Hunting and consumption of mammals and birds by people in urban areas of western Madagascar. Oryx, 44, $411-415$

Reijnen, R. \& Foppen, R. (1994) The effects of car traffic on breeding bird populations in woodland. I. Evidence of reduced habitat quality for willow warblers (Phylloscopus trochilus) breeding close to a highway. Journal of Applied Ecology, 31, 85-94.

Roedenbeck, I.A., Fahrig, L., Findlay, C.S., Houlahan, J.E., JAeger, J.A.G., Klar, N. et al. (2007) The Rauischholzhausen Agenda for road ecology. Ecology and Society, 12, 11.

Schwenk, W.S. \& Donovan, T.M. (2011) A multispecies framework for landscape conservation planning. Conservation Biology, 25, 1010-1021.

Selva, N., Kreft, S., Kati, V., Schluck, M., Jonsson, B.G., Mihok, B. et al. (2011) Roadless and low-traffic areas as conservation targets in Europe. Environmental Management, 48, 865-877.

SinCLAIR, A.R.E. (2010) Road proposal threatens existence of Serengeti. Oryx, 44, 478-479.

Stephens, P.A., Buskirk, S.W., Hayward, G.D. \& Martínez Del Río, C. (2005) Information theory and hypothesis testing: a call for pluralism. Journal of Applied Ecology, 42, 4-12.

Sun, Y., Dong, L., Zhang, Y.Y., Zheng, G.M. \& Browne, S.J. (2009) Is a forest road a barrier for the Vulnerable Cabot's tragopan Tragopan caboti in Wuyishan, Jiangxi, China? Oryx, 43, 614-617.

Sutherland, W.J., Adams, W.M., Aronson, R.B., Aveling, R., BlACKBURN, T.M., BROAD, S. et al. (2009) One hundred questions of importance to the conservation of global biological diversity. Conservation Biology, 23, 557-567.

TELFORD, R.J. \& BiRKS, H.J.B. (2009) Evaluation of transfer functions in spatially structured environments. Quaternary Science Reviews, 28, 1309-1316.

Trombulak, S.C. \& Frissell, C.A. (2000) Review of ecological effects of roads on terrestrial and aquatic communities. Conservation Biology, 14, 18-30.

Turner, W.R., Nakamura, T. \& Dinetti, M. (2004) Global urbanization and the separation of humans from nature. BioScience, $54,585-590$.

VAn der Zande, A.N., ter Keurs, W.J. \& van der Weijden, W.J. (1980) The impact of roads on the densities of four bird species in an 
open field habitat-evidence of a long-distance effect. Biological Conservation, 18, 299-321.

van Langevelde, F., van Dooremalen, C. \& Jaarsma, C.F. (2009) Traffic mortality and the role of minor roads. Journal of Environmental Management, 90, 660-667.

Vermaat, J.E., Goosen, H. \& Omtzigt, N. (2007) Do biodiversity patterns in Dutch wetland complexes relate to variation in urbanisation, intensity of agricultural land use or fragmentation? Biodiversity and Conservation, 16, 3585-3595.

ZAR, J.H. (1996) Biostatistical Analysis. 3rd edition. Prentice Hall International, London, UK.

\section{Biographical sketches}

RicARdo MorÁn-LÓPEZ's research focuses mainly on the study of relationships between species and habitats, species distribution modelling, and the design and evaluation of reserves. JUAN MANUEL SÁnCHeZ GuZmán has carried out research on many aspects of bird ecology and conservation biology, in particular on waterbirds. Alejandra Bettina Perales Casildo uses multivariate analysis to study socioeconomic and ecological data simultaneously. ÓSCAR UCEDA TOLOSA specializes in the use of geographical information systems for spatial analysis in conservation biology. 